\title{
CXCIV. SYNTHESIS OF GLUTATHIONE.
}

\author{
BY CHARLES ROBERT HARINGTON AND THOMAS HOBSON MEAD. \\ From the Department of Pathological Chemistry, University College \\ Hospital Medical School, London.
}

(Received May 31st, 1935.)

THE cysteine-containing peptide isolated from yeast and detected in various animal tissues by Hopkins [1921], which was named by him glutathione, was first regarded as a dipeptide of glutamic acid and cysteine; evidence in favour of the view that it was $\gamma$-glutamylcysteine was apparently provided by the work of Quastel et al. [1923] and of Stewart and Tunnicliffe [1925]. The possibility that this hypothesis was incorrect was first indicated by the investigations of Hunter and Eagles [1927] who obtained preparations of glutathione from yeast, blood and liver which undoubtedly contained another amino-acid in addition to glutamic acid and cysteine.

A reinvestigation of the problem by Hopkins [1930] led to the discovery of an elegant method for the separation of the peptide from biological extracts in the form of its cuprous mercaptide; in this way it was possible to obtain the material in the crystalline condition and it then became apparent that glutathione was in fact a tripeptide containing glutamic acid, cysteine and glycine. The same conclusion was reached almost simultaneously by Kendall, McKenzie and Mason [1930] who employed a different method for the preparation of the crystalline peptide from yeast.

The results of electrometric titration of crystalline glutathione led Pirie and Pinhey [1930] to the conclusion that the peptide was either $\gamma$-glutamylcysteylglycine or $\gamma$-glutamylglycylcysteine. The suggestion advanced by Kendall, McKenzie and Mason [1930] that the glycine and cysteine residues were attached through their amino-groups respectively to the $\alpha$ - and $\gamma$-carboxyl groups of the glutamic acid was rendered most improbable by the observation of Hopkins [1930] that prolonged boiling of an aqueous solution of glutathione resulted in the formation of glutamic acid (or $\alpha$-pyrrolidonecarboxylic acid) and glycylcysteine anhydride.

It had been shown earlier by Quastel et al. [1923], working with impure preparations of glutathione, that oxidation of the peptide with hydrogen peroxide led to a product which on acid hydrolysis yielded succinic acid; this observation was confirmed by Kendall, Mason and McKenzie [1930, 2] for the crystalline peptide and these workers also showed $[1930,1]$ that oxidation of glutathione with hypobromite or chloramine $\mathrm{T}$ led to no scission of peptidelinkages but yielded products from which succinic acid could be isolated after acid hydrolysis.

These observations were consistent only with the supposition that the glutamic acid in glutathione was linked through its $\gamma$-carboxyl group, the $\alpha$-aminocarboxylic grouping being free and therefore exposed to attack by oxidising agents of the type employed. The possibilities for the structure of glutathione were thus reduced to the two suggested by Pirie and Pinhey [1930].

Evidence as to the relative positions occupied by the cysteine and glycine residues in the molecule of glutathione is available from several sources. (a) Scission of the molecule with water can be effected at $62^{\circ}$ [Kendall, Mason and 
McKenzie, 1930, 2] and under these conditions the residue of cysteine and glycine is liberated as a dipeptide and not as an anhydride; condensation of the dipeptide with 2:3:4-trinitrotoluene yields a product from which free glycine can be separated by hydrolysis, indicating that the dipeptide must have been cysteylglycine. (b) Condensation of glutathione with ammonium thiocyanate and acetic anhydride yields a bisthiohydantoin [Nicolet, 1930]; on further condensation with benzaldehyde and treatment with alkali followed by reacidification this gives benzylidenethiohydantoin; such a result could only be obtained if the glycine residue occupied the terminal position in the molecule. (c) Glutathione is partly hydrolysed by carboxypolypeptidase [Grassmann et al., 1930] with liberation of glycine as the only free amino-acid; this again could only occur if glycine were in the terminal position.

It is clear therefore that so far as analytical evidence is concerned the structure of glutathione as $\gamma$-glutamylcysteylglycine is thoroughly established. The description of the final confirmation of this constitution by synthesis is the object of the present paper.

The problem of the synthesis of a peptide with the constitution assigned to glutathione presents two major difficulties. In the first place it is necessary to devise a method of bringing the $\gamma$-carboxyl group of glutamic acid into reaction whilst the $\alpha$-carboxyl group is protected, and in the second place the great lability of the $\gamma$-glutamyl linkage once formed is a serious obstacle in the way of the final removal of acyl and ester groups which are inevitable constituents of the intermediate products of the synthesis. For these reasons the older methods of peptide synthesis are of little help and it was not until the discovery of the benzylcarbonato method by Bergmann and Zervas [1932] that the synthesis of glutathione came within the bounds of possibility. Even this method in its original form however did not provide a solution of all the difficulties, since the removal of the benzylcarbonato residue, according to Bergmann and Zervas, depending as it does on catalytic reduction, could not be effectively carried out with cysteine-containing derivatives.

In the course of some synthetical experiments by one of us (C. R. H.) in conjunction with Dr S. Kishi (to be published later) on the preparation of thyroxinecontaining peptides by the method of Bergmann and Zervas, the difficulty was encountered that removal of the benzylcarbonato residue by catalytic reduction was always accompanied by more or less deiodination. In the search for an alternative reducing agent we were first led to try the mixture of a dilute solution of hydriodic acid in acetic acid with red phosphorus successfully applied by Lamb and Robson [1931] to the reduction of $\alpha$-benzamidocinnamic acid derivatives. The results of preliminary experiments with this reducing agent encouraged us to seek for a further improvement and we finally found that warming at $45-50^{\circ}$ in acetic acid solution with phosphonium iodide afforded a rapid and efficient means of removal of the benzylcarbonato residue, the benzyl group being eliminated as benzyl iodide instead of as toluene in the case of catalytic reduction. In simple cases such as that of benzylcarbonylglycylglycine deacylation could be effected in this manner with a yield of $80 \%$ of the theoretical amount of the dipeptide and even with derivatives of diiodothyronine the yields were quite satisfactory.

An attempt was next made to substitute phosphonium iodide reduction for catalytic hydrogenation in the last stage of the synthesis of glutamine described by Bergmann and Zervas [1933]; treatment of $N$-benzylcarbonylglutamine in acetic acid solution with phosphonium iodide yielded in fact $35 \%$ of the theoretical amount of crystalline glutamine. The success of this experiment encouraged us to hope that the use of phosphonium iodide might also be effective in 
the final stages of the synthesis of glutathione and this expectation has been realised.

The actual course of the synthesis was as follows. $N$-Benzylcarbonylcystine [Bergmann and Zervas, 1932] was converted into the acid chloride and the latter coupled with glycine ester; the product on treatment with phosphonium iodide in acetic acid was converted into cysteylglycyl ester (I) which was conveniently isolated as the hydroiodide. $N$-Benzylcarbonylglutamic acid was then converted into the anhydride which with sodium methoxide in methyl alcohol yielded the $\alpha$-monomethyl ester of $N$-benzylcarbonylglutamic acid [cf. Melville, 1935]; treatment with phosphorus pentachloride converted the latter into the corresponding acid chloride (II) which was coupled with cysteylglycyl ester to give the ester (III).

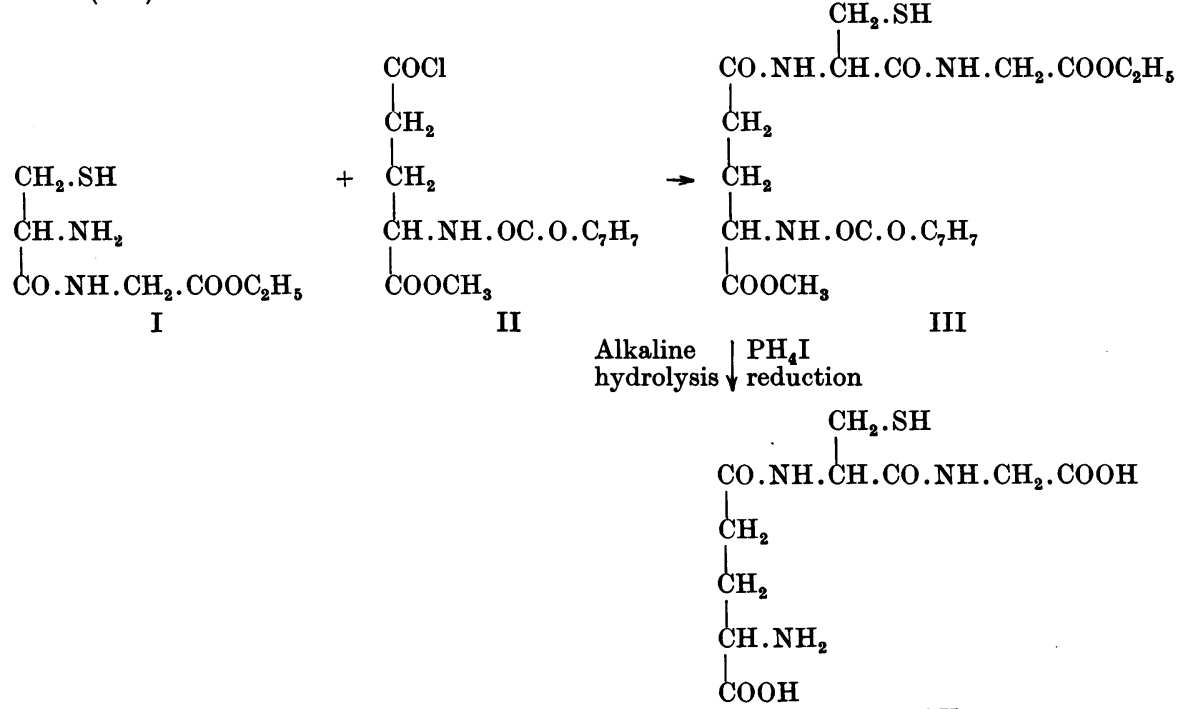

IV

The ester groups were removed from III by very careful hydrolysis in alkaline aqueous dioxan solution and the resulting acid was treated with phosphonium iodide under the usual conditions. From the reaction mixture there was obtained in small yield the tripeptide IV which proved to be identical in every respect with an authentic sample of glutathione obtained from natural sources.

The results of the present work therefore leave no doubt that naturally occurring glutathione is, as has been supposed, $\gamma$-glutamylcysteylglycine.

In view of the work of Stewart and Tunnicliffe [1925] we have thought it of interest to prepare $\gamma$-glutamylcysteine with the aid of the better methods which are now available and a description of this synthesis is included in the present paper. The course of the synthesis follows the lines of that of glutathione itself and calls for no detailed comment.

The synthetic material was distinguished by its remarkable acidity, the $p_{\mathrm{H}}$ of its aqueous solution being about 2.5 ; in the oxidised form it had $[\alpha]_{5461}-120^{\circ}$ as compared with $[\alpha]_{5461}-97 \cdot 4^{\circ}$ for the product of Stewart and Tunnicliffe; the behaviour of the oxidised form of our compound on heating differed from that of the peptide described by the latter authors although the final decomposition points of the two products were the same. The behaviour of an amorphous peptide on heating is however of little significance and in view of the satisfactory analytical 
results recorded by Stewart and Tunnicliffe and of the fact that the divergence between the specific rotations of their product and ours is not very great, we are inclined to think that these authors did in fact have in their hands a somewhat impure preparation of $\gamma$-glutamylcystine.

\section{EXPERIMENTAL.}

Deacylation of N-benzylcarbonyl compounds with phosphonium iodide.

(a) Preparation of glycylglycine. Benzylcarbonylglycylglycine $(0.5 \mathrm{~g}$.) [cf. Bergmann and Zervas, 1932] was dissolved in glacial acetic acid $(20 \mathrm{ml}$.) to which was added phosphonium iodide $(0.5 \mathrm{~g}$.); the solution was contained in a flask provided with a reflux condenser and an inlet tube through which was passed a slow stream of dry hydrogen, the issuing gases being passed through saturated aqueous barium hydroxide and the flask being immersed in a water-bath at 45-50 ${ }^{\circ}$; after $25 \mathrm{~min}$. evolution of carbon dioxide had ceased indicating that the reaction was complete. The solution was evaporated under diminished pressure and the residue taken up in a little water; after neutralisation with ammonia the evaporation was repeated and the residue again taken up in a little water. Addition of alcohol precipitated glycylglycine in colourless plates which were analytically pure. Yield $80 \%$ of the theoretical. (Found: $\mathrm{N}, 21 \cdot 1 \% \cdot \mathrm{C}_{4} \mathrm{H}_{8} \mathrm{O}_{3} \mathrm{~N}_{2}$ requires $\mathrm{N}, 21 \cdot 2 \%$.)

(b) Preparation of glutamine. The benzyl ester of benzylcarbonylglutamine (3.7 g.) [cf. Bergmann and Zervas, 1933] was dissolved in alcohol (50 ml.) and the solution treated at room temperature with $2 N$ sodium hydroxide $(5 \mathrm{ml}$.). After 1 hour the mixture was only faintly alkaline to thymolphthalein; $2 \mathrm{~N}$ hydrochloric acid $(5 \mathrm{ml}$.) was added and the solution evaporated under diminished pressure; the oily residue was taken up in ethyl acetate and the latter extracted with aqueous sodium bicarbonate; careful acidification of the aqueous extract to maximum precipitation yielded an oil which rapidly hardened. (1.7 g.; $61 \%$ of the theoretical.)

The above product was dissolved in acetic acid $(17 \mathrm{ml}$.) and phosphonium iodide ( $1.5 \mathrm{~g}$.) was added; after $45 \mathrm{~min}$. under the conditions described above a further addition of phosphonium iodide $(0.5 \mathrm{~g}$.) was made. Evolution of carbon dioxide ceased after 1.5 hours in all. The solution was evaporated under diminished pressure and the residue taken up in water; the aqueous solution was washed three times with ether, made slightly alkaline with ammonia and concentrated to a low bulk under diminished pressure; addition of alcohol produced a crystalline precipitate which was collected and weighed $(0 \cdot 19 \mathrm{~g}$.$) , a further$ crop of $0.13 \mathrm{~g}$. being obtained by working up the mother liquor; the total yield was therefore $35 \%$ of the theoretical. (Found: $\mathrm{N}$ (Kjeldahl), 19.6\%. $\mathrm{C}_{5} \mathrm{H}_{10} \mathrm{O}_{3} \mathrm{~N}_{2}$ requires $\mathrm{N}, 19 \cdot 2 \%$; on analysis in the van Slyke amino-nitrogen apparatus there was found, after 5 min. shaking, $\mathrm{N}, 18.6 \%$.)

\section{Synthesis of glutathione.}

A few of the compounds described below have already been recorded by Bergmann and Zervas; in these cases we give a brief description of the method of preparation which we have found to be most advantageous.

N-Benzylcarbonylcystyl chloride. $N$-Benzylcarbonylcystine $(11 \mathrm{~g}$.$) , finely$ powdered and thoroughly dried, was suspended in anhydrous chloroform $(60 \mathrm{ml}$.); the mixture was cooled in ice and salt and treated in one portion with powdered phosphorus pentachloride (11 g.); on continued shaking with intermittent cooling almost all passed into solution, after which crystallisation of the 
chloride set in rapidly. Separation of the chloride was completed by addition of an equal volume of anhydrous ether and keeping in the freezing mixture for a short time; the crystals were then collected on a sintered glass funnel with exclusion of atmospheric moisture and used immediately for the next reaction.

$\mathrm{N}$-Benzylcarbonylcystylglycine ethyl ester. The acid chloride prepared as above from $11 \mathrm{~g}$. of $N$-benzylcarbonylcystine, in as finely divided condition as possible, was added in portions with shaking to a solution of glycine ethyl ester (13.5 g.; $50 \%$ excess) in ethyl acetate $\left(200 \mathrm{ml}\right.$.) at $0^{\circ}$; after keeping overnight at $0^{\circ}$ the precipitate was collected, air dried, triturated with water and again collected; it was recrystallised from $n$-propyl alcohol and corresponded in properties with the product described by Bergmann and Zervas [1932]. Yield $11.5 \mathrm{~g}$. or $75 \%$ calculated on the $N$-benzylcarbonylcystine used. (Found: $\mathrm{N}, 8 \cdot 0 \% \cdot \mathrm{C}_{30} \mathrm{H}_{38} \mathrm{O}_{10} \mathrm{~N}_{4} \mathrm{~S}_{2}$ requires $\mathrm{N}, 8.3 \%$.)

Cysteylglycine ethyl ester hydroiodide. N-Benzylcarbonylcystylglycine ethyl ester (11.5 g.) was dissolved in warm glacial acetic acid $(115 \mathrm{ml}$.); the solution was cooled to $50^{\circ}$ and treated with phosphonium iodide (11.5 g.). Reduction was carried out at $45-50^{\circ}$ under the usual conditions, evolution of carbon dioxide being complete in $2 \frac{1}{4}$ hours at which time very little phosphonium iodide was left in excess. The solution was evaporated under diminished pressure and the residue taken up in a little glacial acetic acid; on inoculation with a previous preparation (obtained by precipitation of the acetic acid solution with anhydrous ether) crystallisation set in rapidly. Separation was completed by addition of anhydrous ether and keeping at $0^{\circ}$ for 2 hours; the product was then collected, washed with ether and dried. Yield $95 \%$ of the theoretical.

Cysteylglycine ethyl ester hydroiodide forms long colourless needles from acetic acid, M.P. $115^{\circ}$; it is non-hygroscopic but exceedingly soluble in water; it is readily soluble in alcohol and warm acetic acid but insoluble in organic solvents. (Found: C, $24 \cdot 9 ; \mathrm{H}, 4 \cdot 65 ; \mathrm{N}, 8 \cdot 30 ; \mathrm{I}, 39 \cdot 2 ; \mathrm{S}, 9 \cdot 3 \% . \mathrm{C}_{7} \mathrm{H}_{15} \mathrm{O}_{3} \mathrm{~N}_{2} \mathrm{IS}$ requires $\mathrm{C}$, $25 \cdot 2 ; \mathrm{H}, 4.5 ; \mathrm{N}, 8 \cdot 4 ; \mathrm{I}, 38 \cdot 1 ; \mathrm{S}, 9.5 \%$.)

N-Benzylcarbonylglutamic anhydride. $N$-Benzylcarbonylglutamic acid (45 g.) was covered with freshly distilled acetic anhydride $(120 \mathrm{ml}$.) and the mixture rapidly brought to the boil; boiling was continued for 2 mins. after which the solution was quickly cooled and evaporated as far as possible under diminished pressure on a boiling water-bath. The residue was poured into a beaker, transference being completed with the aid of a little anhydrous chloroform; on cooling and rubbing crystallisation set in and was completed by addition of 2-3 vols. of anhydrous ether. After keeping for a short time in the cold the product was collected, washed with ether and dried; it corresponded in properties with the preparation described by Bergmann and Zervas [1932]. The yield was $88 \%$ of the theoretical.

$\alpha$-Methyl N-benzylcarbonylglutamate. $N$-Benzylcarbonylglutamic anhydride $(35.4 \mathrm{~g}$.) was dissolved in warm anhydrous methyl alcohol $(200 \mathrm{ml}$.); the solution was rapidly cooled and treated, before crystallisation set in, with one equivalent of sodium dissolved in methyl alcohol $(60 \mathrm{ml}$.). After $45 \mathrm{~min}$. the solution was evaporated under diminished pressure; the residue was taken up in water and the aqueous solution washed four times with ether. After acidification with dilute hydrochloric acid the solution was again thoroughly extracted with ether; the ethereal extracts were dried over sodium sulphate and evaporated, the residue being transferred to a flat dish which was placed in a vacuum desiccator over phosphoric oxide. Desiccation was continued in this manner for several days with repeated renewal of the drying agent. The ester formed a colourless very viscous oil. (Found: $\mathrm{N}, 4.75 \% \cdot \mathrm{C}_{14} \mathrm{H}_{17} \mathrm{O}_{6} \mathrm{~N}$ requires $\mathrm{N}, 4 \cdot 75 \%$.) 
$\alpha$-Methyl N-benzylcarbonylglutamatocysteylglycine ethyl ester (III). In the preparation of this compound it was found to be desirable to use a large excess of $\alpha$-methyl $N$-benzylcarbonylglutamate for the preparation of the acid chloride. In the first experiments coupling between this chloride and cysteylglycine ester was effected in pyridine solution; since however it is convenient to employ cysteylglycine ester hydroiodide rather than the free ester which is not easy to isolate and since pyridine is not a strong enough base completely to liberate the free ester from the hydroiodide, it was advantageous to employ diethylamine to liberate the ester and bind the hydrochloric acid formed during the coupling and to carry out the reaction in an indifferent solvent.

$\alpha$-Methyl $N$-benzylcarbonylglutamate $(17 \cdot 7 \mathrm{~g}$.) was dissolved in anhydrous ether (52 $\mathrm{ml}$.); the solution was cooled in ice and salt and treated with powdered phosphorus pentachloride $(\mathbf{1 6} \cdot \mathbf{2}$ g.) ; after shaking with intermittent cooling for 15-20 min. nearly all the phosphorus pentachloride had disappeared. The solution was decanted from excess of phosphorus pentachloride and evaporated under diminished pressure without application of heat and with exclusion of atmospheric moisture; the residue was rubbed up with ligroin, and the crystalline precipitate collected and washed with light petroleum. It was removed from the filter by percolation with three lots of $12 \mathrm{ml}$. of anhydrous chloroform which left an appreciable amount of impurity undissolved.

In the meantime cysteylglycine ethyl ester hydroiodide (10 g.) was suspended in anhydrous chloroform $(75 \mathrm{ml}$.) and treated with diethylamine $(6 \cdot 2 \mathrm{ml}$; 2 mols.); after brief agitation the hydroiodide passed into solution. The clear liquid was cooled in ice and salt and treated gradually with the chloroform solution of the acid chloride prepared as described above; $1 \mathrm{ml}$. more of diethylamine was introduced towards the end of the addition of acid chloride in order to maintain an alkaline reaction. After 5 hours at room temperature the solution was filtered and the filtrate washed four times with water, once with dilute sulphuric acid and once again with water; it was then dried over sodium sulphate and evaporated under diminished pressure. The residue was taken up in boiling ethyl acetate $(150 \mathrm{ml}$.) and treated with 1-1.5 vols. of light petroleum (B.P. $100-120^{\circ}$ ); after keeping at $0^{\circ}$ for some hours the product was collected, washed with light petroleum and dried. Crude yield $8.4 \mathrm{~g}$. or $58 \%$ calculated on the cysteylglycine ethyl ester hydroiodide employed.

During the various manipulations a certain amount of oxidation of the product to the sparingly soluble disulphide form had occurred; this made purification difficult and the only method of obtaining a satisfactory preparation consisted in the wasteful process of reduction of the crude product with zinc dust followed by precipitation as the cuprous mercaptide [cf. Pirie, 1931]. The crude material (1 g.) was dissolved in hot alcohol $(50 \mathrm{ml}.) ; 7.5 \mathrm{ml}$. of $5 \mathrm{~N}$ sulphuric acid and $2.5 \mathrm{ml}$. of water were added and the warm solution was shaken with zinc dust for 15 mins.; the solution was then filtered, the filter being washed with $2 / 3 \mathrm{~N}$ sulphuric acid in $80 \%$ alcohol. The filtrate and washings were treated at boiling point with an alcoholic suspension of cuprous oxide which was added drop by drop with careful avoidance of excess. The white precipitate was separated on the centrifuge and washed three times with alcohol; it was then suspended in alcohol and decomposed at boiling point with a vigorous stream of hydrogen sulphide. The cuprous sulphide was separated on the centrifuge and washed with alcohol, the washing being added to the first solution from which crystals had already begun to separate; after heating the combined alcoholic liquors to obtain a clear solution an equal volume of water was added and the whole set aside at $0^{\circ}$ overnight; next day the crystalline precipitate was collected, 
washed with dilute alcohol and dried. Yield 0.55 g. The ester crystallises in fine colourless needles which tend to form spherical aggregates, M.P. $173^{\circ}$. It is somewhat sparingly soluble in alcohol. (Found: $\mathrm{C}, 52 \cdot 28,52 \cdot 23 ; \mathrm{H}, 6 \cdot 06,6 \cdot 08$, $\mathrm{N}, 8 \cdot 99,8 \cdot 83 ; \mathrm{S}, 6 \cdot 17,6 \cdot 05 \% \cdot \mathrm{C}_{21} \mathrm{H}_{29} \mathrm{O}_{8} \mathrm{~N}_{3} \mathrm{~S}$ requires $\mathrm{C}, 52 \cdot 2 ; \mathrm{H}, 6 \cdot 0 ; \mathrm{N}, 8 \cdot 7$; $\mathrm{S}, 6 \cdot 6 \%$.)

$\mathrm{N}$-Benzylcarbonyl- $\gamma$-glutamylcysteylglycine. The hydrolysis of the above ester offered considerable difficulties; no success was achieved by working in aqueous or aqueous-alcoholic solution and it was not until aqueous dioxan was tried as a medium that a satisfactory preparation of the acid was obtained. The purified ester (4.6 g.) was dissolved with warming in purified dioxan $(50 \mathrm{ml}$.); after addition of thymolphthalein the solution was rapidly titrated with $N$ sodium hydroxide until faintly blue (this required almost exactly one equivalent of alkali and corresponded to the $\mathrm{SH}$ group); two more equivalents of $\mathrm{N} \mathrm{NaOH}$ were then added and the mixture kept at room temperature for $1 \frac{1}{4}$ hours. At the end of this period the sodium hydroxide used was neutralised exactly by addition of dilute hydrochloric acid; the dioxan was then removed by distillation under diminished pressure and the aqueous residue extracted with ethyl acetate. The latter was extracted with aqueous sodium bicarbonate and the aqueous extract, after washing with ether, was acidified; the oil which separated rapidly hardened and was collected, washed with water and dried. Yield $3.8 \mathrm{~g}$. or $90 \%$ of the theoretical.

The crude product formed a colourless granular powder, M.P. $163^{\circ}$ (decomp.) after sintering. (Found: $\mathrm{N}, 9 \cdot 2 \% . \mathrm{C}_{18} \mathrm{H}_{23} \mathrm{O}_{8} \mathrm{~N}_{3} \mathrm{~S}$ requires $\mathrm{N}, 9.5 \%$.) $38.9 \mathrm{mg}$. required $7.9 \mathrm{ml}$. $\mathrm{N} / 50 \mathrm{NaOH}$ to neutralise to methyl red; $\mathrm{C}_{18} \mathrm{H}_{23} \mathrm{O}_{8} \mathrm{~N}_{3} \mathrm{~S}$ titrating as a dibasic acid requires $8.8 \mathrm{ml}$. of $N / 50$.

For analysis a small sample was purified through the cuprous mercaptide; after recovery it was obtained from dilute alcohol as colourless needles, M.P. $166^{\circ}$ after sintering. (Found: $\mathrm{C}, 48 \cdot 3 ; \mathrm{H}, 5 \cdot 45 ; \mathrm{N}, 9 \cdot 2 \% . \mathrm{C}_{18} \mathrm{H}_{23} \mathrm{O}_{8} \mathrm{~N}_{3} \mathrm{~S}$ requires $\mathrm{C}$, $49 \cdot 0 ; \mathrm{H}, 5 \cdot 2 ; \mathrm{N}, 9.5 \%$.)

$\gamma$-Glutamylcysteylglycine-glutathione. $N$-Benzylcarbonylglutamylcysteylglycine ( $3 \mathrm{~g}$. crude) was dissolved in warm glacial acetic acid $(30 \mathrm{ml}$.) and treated with pulverised phosphonium iodide $(2 \cdot 4 \mathrm{~g}$.) ; the reduction was carried out as usual. During the reaction a sticky precipitate separated on the walls of the flask and tended to coat the phosphonium iodide and render the latter nonreactive; further additions of 2 and $1 \mathrm{~g}$. of phosphonium iodide were therefore made at 70 and $120 \mathrm{~min}$. respectively. After $140 \mathrm{~min}$. in all the acetic acid was decanted and the precipitate rubbed up with a small amount of alcohol into which it passed into solution with decomposition of excess phosphonium iodide; the acetic acid was treated with excess of anhydrous ether and the precipitate separated and taken up in the minimum of alcohol; the combined alcoholic solutions were then again precipitated with anhydrous ether. The crude peptide hydroiodide so obtained was rubbed up with ether until granular, separated at the centrifuge and taken up in the minimum of water; $5 \mathrm{~N}$ sodium hydroxide was cautiously added to $p_{\mathrm{H}} 2.9$ followed by excess of alcohol; the crude peptide was redissolved in a little water and again precipitated with warm acetone to complete removal of iodide. The precipitate was taken up in $0.5 \mathrm{~N}$ sulphuric acid and the filtered solution treated at $50^{\circ}$ with a suspension of cuprous oxide; the mercaptide separated with the characteristic silky sheen noted by Hopkins [1930]. The mother liquor was treated with mercuric sulphate to maximum precipitation and the mercury compound separated, washed and decomposed in the usual manner; renewed treatment of the recovered solution with cuprous oxide gave a small further amount of mercaptide. 
The combined precipitates of cuprous mercaptide were washed at the centrifuge until free from sulphate (9 washings), suspended in water and decomposed with hydrogen sulphide; the filtrate from the cuprous sulphide was concentrated in a desiccator over phosphoric oxide to a low bulk and left overnight in a desiccator containing sodium hydroxide and a dish of alcohol and evacuated to $300 \mathrm{~mm}$. Next morning the moist, entirely crystalline residue was collected with the aid of alcohol and dried at $56^{\circ}$ in a vacuum over phosphoric oxide. Yield $223 \mathrm{mg}$.

The material so obtained was pure; it could be recrystallised by solution in water and concentration in a desiccator in presence of alcohol as described. It crystallised in colourless prisms and on rapid heating melted sharply at $190^{\circ}$ with effervescence but no immediate coloration; this behaviour was precisely similar to those of authentic natural glutathione and of a mixture of the natural and synthetic products. (Found: C, 39.1; H, 5.55; N, 13.75, 13.66; S, 10.12, 10.27. $\mathrm{C}_{10} \mathrm{H}_{17} \mathrm{O}_{6} \mathrm{~N}_{3} \mathrm{~S}$ requires $\mathrm{C}, 39 \cdot 1 ; \mathrm{H}, 5 \cdot 5 ; \mathrm{N}, 13 \cdot 7 ; \mathrm{S}, 10 \cdot 4 \%$.)

The synthetic peptide had $[\alpha]_{5461}-21 \cdot 0^{\circ}$ in water $(c=2 ; 1 \mathrm{dm}$. tube). Precisely the same value was found for authentic glutathione under the same conditions. Hopkins $[1930]$ gives $[\alpha]_{5461}-18 \cdot 5^{\circ}$.

Iodine titration of synthetic glutathione. $10 \mathrm{mg}$. of the synthetic peptide were dissolved in $5 \%$ potassium iodide and treated with $5 \mathrm{ml}$. of $0.01 \mathrm{~N}$ iodine solution; the excess of iodine required $1.75 \mathrm{ml} .0 \cdot 01 \mathrm{~N}$ thiosulphate. The iodine used in oxidising the SH group therefore amounted to $3.25 \mathrm{ml}$. of $0.01 \mathrm{~N}$ (calc. $3.26 \mathrm{ml} .0 .01 \mathrm{~N}$ ).

Rotation of oxidised glutathione. No values for the rotation of oxidised glutathione prepared from the pure thiol compound appear to be available in the literature; for further identification of the natural and synthetic products therefore the following experiment was carried out. Synthetic glutathione (10 mg.) was dissolved in water $(0.335 \mathrm{ml}$.) ; to this were added a minute trace of copper sulphate and the theoretical amount of hydrogen peroxide in water $(0 \cdot 165 \mathrm{ml}$.) to oxidise the glutathione to the disulphide form; a similar experiment was set up with natural glutathione. After 3 hours at room temperature the nitroprusside reaction had disappeared from both solutions; the solution of synthetic oxidised glutathione had $\alpha_{5461}-1.07^{\circ}$ in a $0.5 \mathrm{dm}$. tube, giving $[\alpha]_{5461}-107^{\circ}$ and the natural product under the same conditions had $\alpha_{5461}-1.08$ giving $[\alpha]_{5461}-108^{\circ}$.

Formation of cystylglycyl anhydride from synthetic glutathione. A curious property of glutathione discovered by Hopkins [1930] is the ease with which the peptide is decomposed on boiling in aqueous solution with liberation of glutamic acid (largely in the form of $\alpha$-pyrrolidonecarboxylic acid) and cystylglycyl anhydride. This observation has been repeated with synthetic glutathione. The synthetic peptide $(77 \mathrm{mg}$.) was oxidised to the disulphide form with the theoretical amount of hydrogen peroxide and the solution (total volume $3 \mathrm{ml}$.) boiled under reflux for 42 hours; concentration to a low volume on the steam-bath resulted in separation of crystalline material which after collection and drying amounted to $7 \cdot 8 \mathrm{mg}$. After recrystallisation from water this formed large colourless needle-shaped crystals, M.P. 261-262 ${ }^{\circ}$ (decomp.). Hopkins [1930] gives M.P. $262^{\circ}$.

\section{Synthesis of $\gamma$-glutamylcysteine.}

$\alpha-M e t h y l \mathrm{~N}$-benzylcarbonylglutamatocysteine ethyl ester. The acid chloride from $15 \mathrm{~g}$. of $\alpha$-methyl $N$-benzylcarbonylglutamate prepared as above was dissolved in chloroform $(30 \mathrm{ml}$.); cystine ethyl ester hydrochloride $(7 \mathrm{~g}$.) was suspended in anhydrous chloroform (75 ml.) and treated with diethylamine $(7 \cdot 8 \mathrm{ml}$.$) ; to the$ 
resulting clear solution of cystine ester the acid chloride was added gradually with shaking and strong cooling; towards the end of the process further diethylamine (1.9 ml.) was added in order to maintain an alkaline reaction. After keeping overnight the solution was washed three times with water, once with dilute sulphuric acid (excess) and once again with water; it was then filtered through a dry paper, dried over sodium sulphate and evaporated under diminished pressure. The oily residue was taken up in a little ethyl acetate and treated gradually with light petroleum (B.P. 100-120 $)$; the precipitate, at first oily, rapidly became hard and granular. Yield $7 \cdot 2 \mathrm{~g} .(44 \%$ of the theoretical calculated on the cystine ester hydrochloride).

For purification the crude ester was reduced to the thiol form by treatment with zinc dust in warm dilute alcohol containing sulphuric acid and then precipitated as the cuprous mercaptide. On recovery the compound formed fine colourless needles from dilute alcohol, M.P. $97^{\circ}$. Considerable loss was involved in the purification. (Found: $\mathrm{C}, 53 \cdot 3 ; \mathrm{H}, 6 \cdot 0 ; \mathrm{N}, 6 \cdot 4 ; \mathrm{S}, 7 \cdot 5 \% \cdot \mathrm{C}_{19} \mathrm{H}_{26} \mathrm{O}_{7} \mathrm{~N}_{2} \mathrm{~S}$ requires $\mathrm{C}, 53 \cdot 5 ; \mathrm{H}, 6 \cdot \mathrm{I} ; \mathrm{N}, 6 \cdot 6 ; \mathrm{S}, 7 \cdot 5 \%$.)

$\mathrm{N}$-Benzylcarbonyl- $\gamma$-glutamylcysteine. The above ester $(2.5 \mathrm{~g}$.; purified) was dissolved in purified dioxan $(12.5 \mathrm{ml}) ; 2$ drops of thymolphthalein were added and $N$ sodium hydroxide was run in to the first permanent blue colour $(6 \cdot 0 \mathrm{ml}$. used; theoretical for 1 equiv. $5 \cdot 9 \mathrm{ml}$.); $11.8 \mathrm{ml}$. $N$ sodium hydroxide were then added and the mixture kept at room temperature for $1 \frac{1}{4}$ hours. After treatment with $2 N$ hydrochloric acid equivalent to the total sodium hydroxide used the dioxan was removed by distillation under diminished pressure. The residue was extracted with ethyl acetate and the latter in turn extracted with aqueous sodium bicarbonate; the alkaline solution was washed with ether, acidified and again extracted with ethyl acetate. The ethyl acetate solution was dried over sodium sulphate and evaporated to a low bulk under diminished pressure; addition of light petroleum to the residue caused the acid to separate as an oil which became cheesy but not completely solid. The compound was used for the next reaction without further purification.

$\gamma$-Glutamylcysteine. $\quad N$-Benzylcarbonyl- $\gamma$-glutamylcysteine (1.8 g.; crude) was dissolved in glacial acetic acid $(18 \mathrm{ml}$.) and reduced as usual with phosphonium iodide $(2 \cdot 45 \mathrm{~g}$. in all; $1.7 \mathrm{~g}$. at beginning and $0.75 \mathrm{~g}$. after 1 hour $)$; the reaction was complete in 2 hours. The solution was then evaporated under diminished pressure and the residue taken up in a little water; after removal of benzyl iodide by extraction with ether the aqueous solution was adjusted to $p_{\mathrm{H}} 2 \cdot 6$ (estimated isoelectric point of the peptide) by addition of $5 \mathrm{~N}$ sodium hydroxide. Alcohol was then added but evidently failed to produce complete precipitation; the $p_{\mathrm{H}}$ was therefore raised to about $3 \cdot 4$ by addition of saturated aqueous sodium acetate when maximum flocculation occurred; precipitation was completed by addition of acetone. The precipitate was separated at the centrifuge, again taken up in a little water and precipitated with alcohol, this process being repeated twice more to remove the last traces of iodine. The product was then purified through its cuprous mercaptide and separated after recovery from the latter in the same way as described for glutathione; it was finally obtained in two crops, the first consisting of well formed prismatic crystals $(177 \mathrm{mg}$.) and the second of crystalline but less pure material $(85 \mathrm{mg}$.). The compound melted with decomposition at $167^{\circ}$ after sintering. It possessed very marked acidic properties, having in aqueous solution $p_{\mathrm{H}}$ about $2 \cdot 5$. (Found: $\mathrm{C}, 37 \cdot 6 ; \mathrm{H}, 5 \cdot 6 ; \mathrm{N}, 11 \cdot 1$, $\mathrm{S}, 12 \cdot 6 \%$. $\mathrm{C}_{8} \mathrm{H}_{14} \mathrm{O}_{5} \mathrm{~N}_{2} \mathrm{~S}$ requires $\mathrm{C}, 38 \cdot 4 ; \mathrm{H}, 5 \cdot 6 ; \mathrm{N}, 11 \cdot 2 ; \mathrm{S}, 12 \cdot 8 \%$.)

Iodine titration. The peptide $(10 \mathrm{mg}$.) was dissolved in $5 \%$ potassium iodide $(5 \mathrm{ml}$.) and treated with $0.01 \mathrm{~N}$ iodine solution $(5 \mathrm{ml}$.); the excess of iodine 
required $0.6 \mathrm{ml}$. of $0.01 \mathrm{~N}$ sodium thiosulphate. The iodine used up therefore amounted to $4.4 \mathrm{ml}$. of $0 \cdot 01 \mathrm{~N}$ as against the theoretical amount of $4 \cdot 0 \mathrm{ml} .0 \cdot 01 \mathrm{~N}$.

Rotation of $\gamma$-glutamylcysteine and $\gamma$-glutamylcystine. $\gamma$-Glutamylcysteine (110 mg.) was dissolved in water $\left(10 \mathrm{ml}\right.$.); the solution had $\alpha_{5461}+0 \cdot 15^{\circ}$ in a $1 \mathrm{dm}$. tube, giving $[\alpha]_{5461}+13 \cdot 6^{\circ}$.

$9 \cdot 7 \mathrm{ml}$. of the above solution, corresponding to $106.7 \mathrm{mg}$. of the peptide, were then oxidised with the theoretical amount of hydrogen peroxide in presence of a trace of copper sulphate; after 2 hours the nitroprusside reaction had disappeared and the solution had $\alpha_{5461}-1 \cdot 19^{\circ}$ in a $1 \mathrm{dm}$. tube, giving $[\alpha]_{5461}-120^{\circ}$ for the disulphide form of the peptide.

$\gamma$-Glutamylcystine. A sample of the oxidised form of the dipeptide was obtained by evaporating the above solution to dryness in a vacuum desiccator, taking up the glassy residue in a little water and precipitating with excess of absolute alcohol. Separated in this way, it formed a non-hygroscopic amorphous powder; the behaviour on heating was curious since the material swelled up the capillary tube at a little over $100^{\circ}$ after which no further change occurred until $187^{\circ}$ when brisk decomposition set in. (Stewart and Tunnicliffe [1925] give $187^{\circ}$ after softening at $165-170^{\circ}$ as the melting point of their product.) (Found: $\mathrm{N}, 10 \cdot 6 \% \cdot \mathrm{C}_{16} \mathrm{H}_{26} \mathrm{O}_{10} \mathrm{~N}_{4} \mathrm{~S}_{2}$ requires $\mathrm{N}, 11 \cdot 2 \%$.)

\section{REFERENCES.}

Bergmann and Zervas (1932). Ber. deutsch. chem. Ges. 65, 1192. - (1933). Ber. deutsch. chem. Ges. 66, 1288.

Grassmann, Dyckerhoff and Eibeler (1930). Z. physiol. Chem. 189, 112.

Hopkins (1921). Biochem. J. 15, 286. (1930). J. Biol. Chem. 84, 269.

Hunter and Eagles (1927). J. Biol. Chem. 72, 147.

Kendall, McKenzie and Mason (1930). J. Biol. Chem. 84, 657.

- Mason and McKenzie (1930, 1). J. Biol. Chem. 87, 55.

- - (1930, 2). J. Biol. Chem. 88, 409.

Lamb and Robson (1931). Biochem. J. 25, 1231.

Melville (1935). Biochem. J. 29, 179.

Nicolet (1930). J. Biol. Chem. 88, 389.

Pirie (1931). Biochem. J. 25, 613.

— and Pinhey (1930). J. Biol. Chem. 84, 321.

Quastel, Stewart and Tunnicliffe (1923). Biochem. J. 17, 586.

Stewart and Tunnicliffe (1925). Biochem. J. 19, 207. 